\title{
PEMBERDAYAAN MASYARAKAT UKM KERIPIK SINGKONG RASA GADUNG SEBAGAI PRODUK UNGGULAN DAERAH DESA SIDOMUKTI KECAMATAN JENAWI KABUPATEN KARANGANYAR
}

\author{
${ }^{1)}$ Dian Kresnadipayana, ${ }^{2)}$ Guruh Sri Pamungkas, ${ }^{3)}$ Dian Indriana Hapsari \\ ${ }^{1)}$ Fakultas Ilmu Kesehatan, Universitas Setia Budi Surakarta \\ ${ }^{2), 3)}$ Fakultas Ekonomi, Universitas Setia Budi Surakarta \\ 1) email: diankresna@setiabudi.ac.id; dian.kresnadipayana@gmail.com
}

\begin{abstract}
ABSTRAK
Village Sidomukti Jenawi District Karanganyar Central Java, there is the production of cassava chips but has a sense of gadung that the process of making cassava chips flavor gadung. Mrs. Warti is a pioneer of SMEs Cassava Chips Rasa Gadung where the SMEs have many groups that have many members one of them is Sri Rejeki Group which was established in 2006. The second partner in this service is Mukti Rahayu Women's Group in Sidomukti Village, Jenawiyar District, Jenawi Regency, where it was established in 2009 with the board, among others; Mrs. Yani as Chairman, Mrs. Suharni as Secretary and Mrs. Darsimi as Treasurer. Some partner problems are lack of raw materials, lack of production support tools, weak marketing system and promotion, weak financial management. Some of the solutions offered are the use of appropriate organic fertilizer (probiotics), cooperation with local government and private sector, procurement of production tools and financial management training based on application program/ financial software.
\end{abstract}

Keywords: excellent products, cassava flavored cassava chips

\section{PENDAHULUAN}

Kondisi alam Kecamatan Jenawi yang pegunungan, maka sebagian besar penduduknya mempunyai mata pencaharian di sektor pertanian (petani sendiri dan buruh tani). Kemudian sebagai buruh industri/karyawan swasta, buruh bangunan dan pedagang. Selebihnya adalah sebagai pengusaha, di sektor pengangkutan, PNS/ TNI/Polri, pensiunan, jasa-jasa dan lainlain. Pertanian tanaman bahan makanan merupakan salah satu sektor dimana produk yang dihasilkan menjadi kebutuhan pokok hidup rakyat. Kecamatan Jenawi sebagian tanahnya merupakan tanah pertanian yang memiliki potensi cukup baik bagi pengembangan tanaman agro industri. Data dari SubDin Tan. Pangan dan Hortikultura Kabupaten Karanganyar selama tahun 2014 diperoleh produksi padi sawah sebanyak $7.259 \mathrm{kwt}$ dari luas panen 1.190 ha, jagung sebanyak $3.680 \mathrm{kwt}$ dari luas panen 526 ha, ketela pohon sebanyak $11.130 \mathrm{kwt}$ dari luas panen 376 ha dan kacang tanah sebanyak 40 kwt dari luas panen 31 ha. Populasi ternak yang banyak diusahakan di Kecamatan Jenawi pada tahun 2014 adalah ,sapi potong 3.028ekor, kambing 2.226 ekor domba 1.785 ekor, ayam ras 17.770 ekor, 27.700 ekor ayam buras dan kelinci 80 ekor (Badan Pusat Statistik, 2014).

Keripik singkong atau ketela sangat banyak disukai oleh semua kalangan, baik tua maupun muda, kalangan bawah ataupun kalangan atas, sebagai makanan cemilan. Biasanya keripik singkong atau ketela ini merupakan makanan yang disajikan untuk tamu ataupun sebagai teman untuk 
ngobrol-ngobrol. Pangsa pasar yang besar pembuat keripik singkong di Indonesia sangat banyak bermunculan, selain itu juga karena proses pembuatan kripik singkong pun bisa dilakukan dengan cara tradisional sekalipun. Keripik singkong dengan beragam aneka rasa juga sangat bermunculan, mulai dari rasa gurih, manis, asem, pedas, hingga rasa lainnya. Dibandingkan dengan kripik tales, memang kripik singkong lebih banyak disukai. Karena kripik tales harganya agak lebih mahal, namun keripik tales memiliki rasa yang lebih gurih dan renyah dibanding keripik singkong.

Desa Sidomukti Jenawi Kab. Karanganyar Jawa Tengah, terdapat produksi keripik singkong namun memiliki rasa gadung (gadung : sejenis umbi rasanya mirip dengan tales). Sesuai dengan wawancara dengan Ibu Warti (Gambar 1) bahwa proses pembuatan kripik singkong rasa gadung ini sebenarnya mirip dengan proses pembuatan keripik singkong pada umumnya, namun di sini singkong atau ketela melalui proses yang agak lebih lama dalam masa perendaman dan direbus sehingga rasa dari ketela ini akan hilang sendirinya, dan timbul rasa seperti gadung.

Gadung sejenis umbi yang memiliki banyak getahnya. Jika dimakan namun masih terdapat getahnya, maka akan bisa mengakibatkan rasa pusing gatal di lidah. Jika dibuatkan keripik, proses pembersihan gadung lebih terasa sulit dengan melakukan pembersihan getah secara berulang - ulang. Rasa gadung sebenarnya mirip dengan tales yang sudah dikenal oleh masyarakat. Jika sudah pernah merasakan keripik tales, mungkin rasa ini sudah tidak asing lagi. Karena lebih gurih namun tidak membuat pahit atau sepet jika dimakan terus menerus. Berbeda dengan keripik singkong, jika kita makan dalam waktu lama, dimulut akan terasa panas, atau bahkan ada yang terasa pahit atau sepet. Ibu Warti sebagai perintis dalam pembuatan keripik singkong rasa gadung yang juga sebagai produsen ketela rasa gadung ini, memberikan beberapa langkah untuk membuat kripik singkong rasa gadung ini. Rasa ketela akan hilang selama proses perendaman dan perebusan secara berulang - ulang tersebut. Dengan demikian rasa gadung yang hampir tidak memiliki rasa, dapat dimunculkan pada ketela ini. Ibu Warti merupakan perintis UKM Keripik Singkong di mana UKM tersebut mempunyai kelompok yang banyak memiliki anggota yang banyak salah satunya adalah Kelompok Sri Rejeki yang berdiri pada tahun 2006. Produksi keripik singkong tersebut mencapai 100-200 kg plastik besar per hari. Kelompok Sri Rejeki mempunyai pengurus yaitu Ibu Warti sebagai Ketua, Ibu Sukarmi sebagai Sekretaris, Ibu Sukarni sebagai Bendahara. Sebagai bentuk dari inovasi produk unggulan untuk mempertahankan tradisi produksi keripik singkong rasa gadung, Kelompok Sri Rejeki juga menyelenggarakan kegiatan pertemuan antar anggota dalam hal koordinasi antar anggota kelompok.

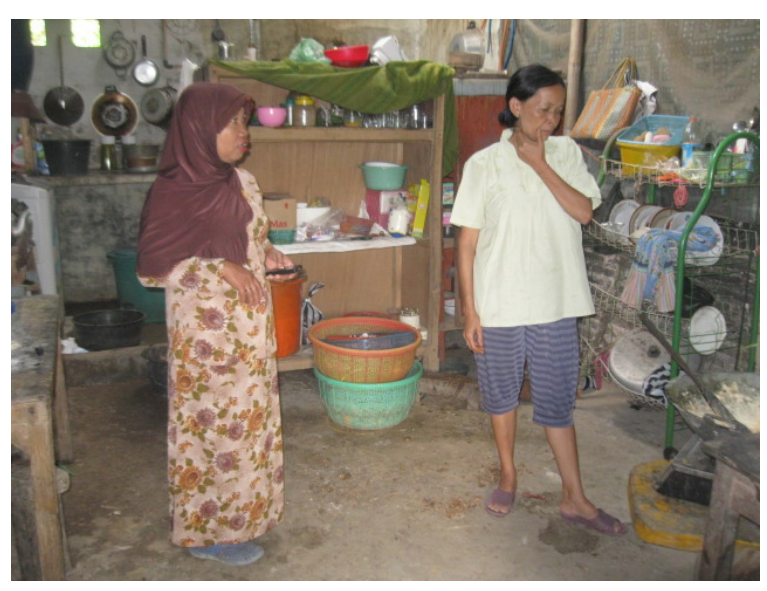

Gambar 1. Pengusul IbPUD Melakukan Wawancara dengan Ibu Warti (kanan) dan Didampingi Ibu Bayan (kiri) Tentang Proses Pembuatan Keripik Singkong Rasa Gadung.

Gadung sejenis umbi yang memiliki banyak getahnya. Jika dimakan namun masih terdapat getahnya, maka akan bisa mengakibatkan rasa pusing gatal di lidah. Jika dibuatkan keripik, proses pembersihan gadung lebih terasa sulit dengan melakukan pembersihan getah secara berulang - ulang. Rasa gadung sebenarnya mirip dengan tales yang sudah dikenal oleh masyarakat. Jika sudah pernah merasakan keripik tales, 
mungkin rasa ini sudah tidak asing lagi. Karena lebih gurih namun tidak membuat pahit atau sepet jika dimakan terus menerus. Berbeda dengan keripik singkong, jika kita makan dalam waktu lama, dimulut akan terasa panas, atau bahkan ada yang terasa pahit atau sepet. Ibu Warti sebagai perintis dalam pembuatan keripik singkong rasa gadung yang juga sebagai produsen ketela rasa gadung ini, memberikan beberapa langkah untuk membuat kripik singkong rasa gadung ini. Rasa ketela akan hilang selama proses perendaman dan perebusan secara berulang - ulang tersebut. Dengan demikian rasa gadung yang hampir tidak memiliki rasa, dapat dimunculkan pada ketela ini.

\section{METODE PELAKSANAAN}

Kegiatan ini terbagi menjadi 3 yaitu: (1) Peningkatan Promosi, Pemasaran dan Kerja Sama; (2) Peningkatan Bahan Baku dan Produksi; (3) Peningkatan Manajemen Keuangan dan Pemasaran.

\section{HASIL PELAKSANAAN KEGIATAN}

Berdasarkan hasil pelaksaan kegiatan IbPUD Keripik Singkong Rasa Gadung Sebagai Produk Unggulan Daerah Desa Sidomukti Kecamatan Jenawi Kabupaten Karanganyar dapat disampaikan evaluasi sebagai berikut. Secara umum kegiatan dilaksanakan dengan baik dan dapat dikatakan berhasil dalam arti luaran yang diharapkan telah tercapai, hal ini dapat dilihat pada setiap tahapan kegiatan yang telah dilakukan.

\section{Peningkatan Promosi, Pemasaran dan Kerja Sama}

Pada bulan Februari 2017 Tim IbPUD Jenawi melakukan pendekatan awal dengan Pemerintah Daerah khususnya Dinas Perdagangan, Tenaga Kerja dan Koperasi. Beberapa tindak lanjut tersebut adalah diikutnya Tim IbPUD dalam pameran pada tingkat Kabupaten Karanganyar. Pameran dilaksanakan di Rumah Dinas Bupati Karanganyar. Pameran disajikan Gambar 2, 3, dan 4.

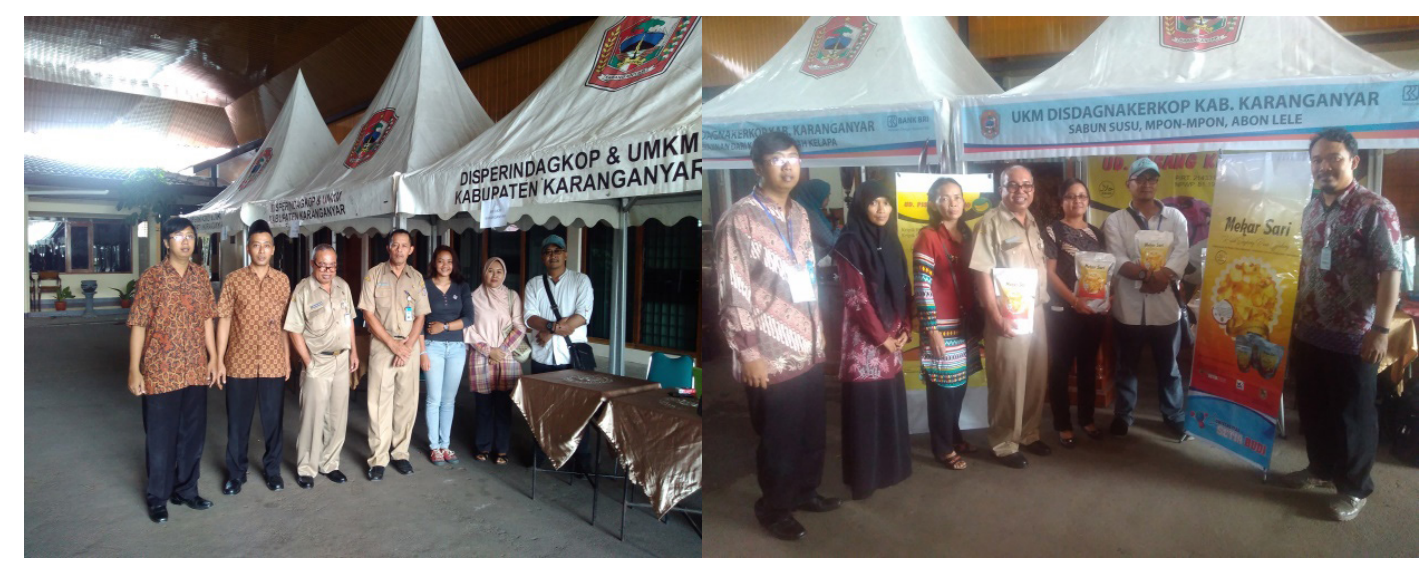

Gambar 2 dan 3. Persiapan Pameran Produk Unggulan Kabupaten Karanganyar

Pada tanggal 21 Februari telah dilakukan Pameran Produk Unggulan Kabupaten Karanganyar yang dihadiri Ibu Presiden dan Wakil Presiden beserta para Ibu Menteri. 


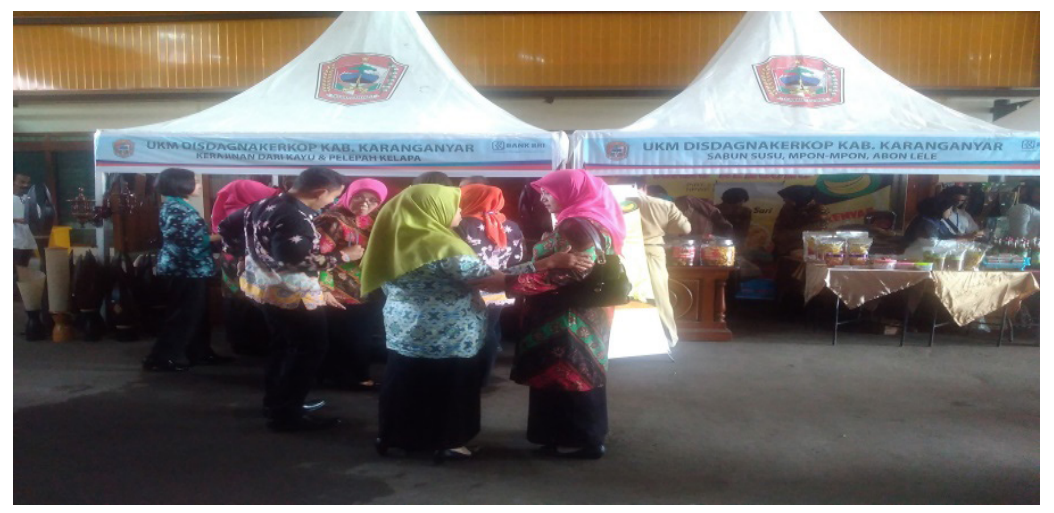

Gambar 4. Pengunjung Pameran Produk Unggulan Kabupaten Karanganyar

Pada 30 Maret 2017 Tim IbPUD Jenawi diberikan kesempatan dalam Pameran SCIENTIFIC FAIR USB 2017. Pameran dilaksanakan di Universitas Setia Budi sebagai ajang hasil penelitian dan pengabdian masyarakat dosen. Pameran disajikan Gambar 5 dan 6.
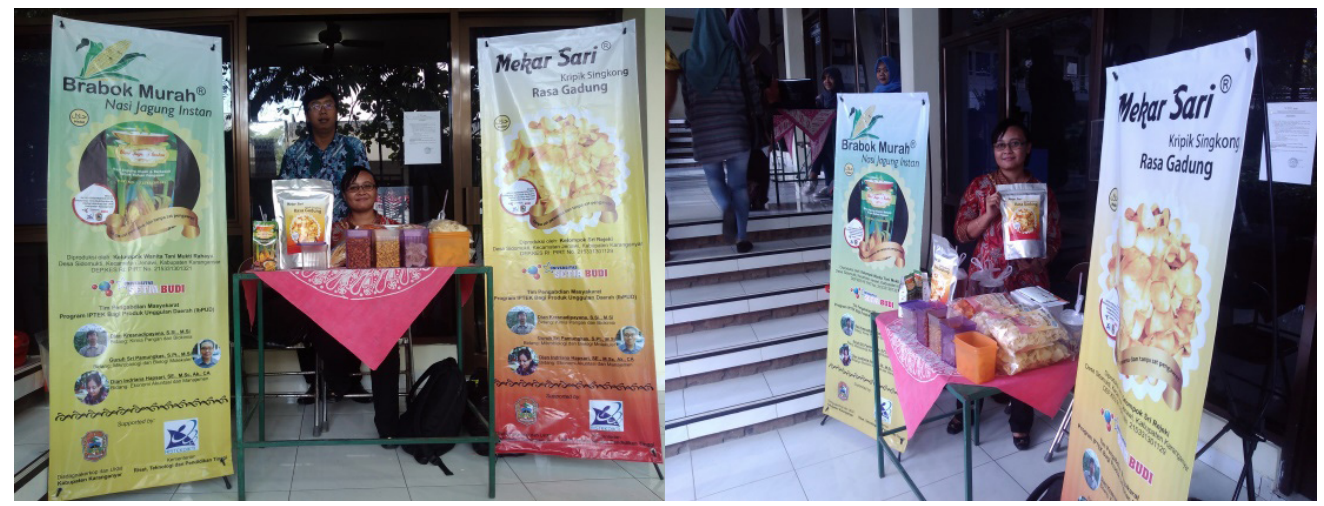

Gambar 5 dan 6. Pameran SCIENTIFIC FAIR USB 2017

Pada Pameran SCIENTIFIC FAIR USB 2017 juga hadir beberapa pengurus HIPMI Solo (Himpunan Pengusaha Muda Indonesia). Sebagai tindak lanjut tersebut telah diadakan MoU atas nama Unversitas di mana salah satu delegasi dalam tindak lanjut MoU tersebut adalah Tim IbPUD. Pertemuan tersebut disajikan Gambar 7 dan 8.

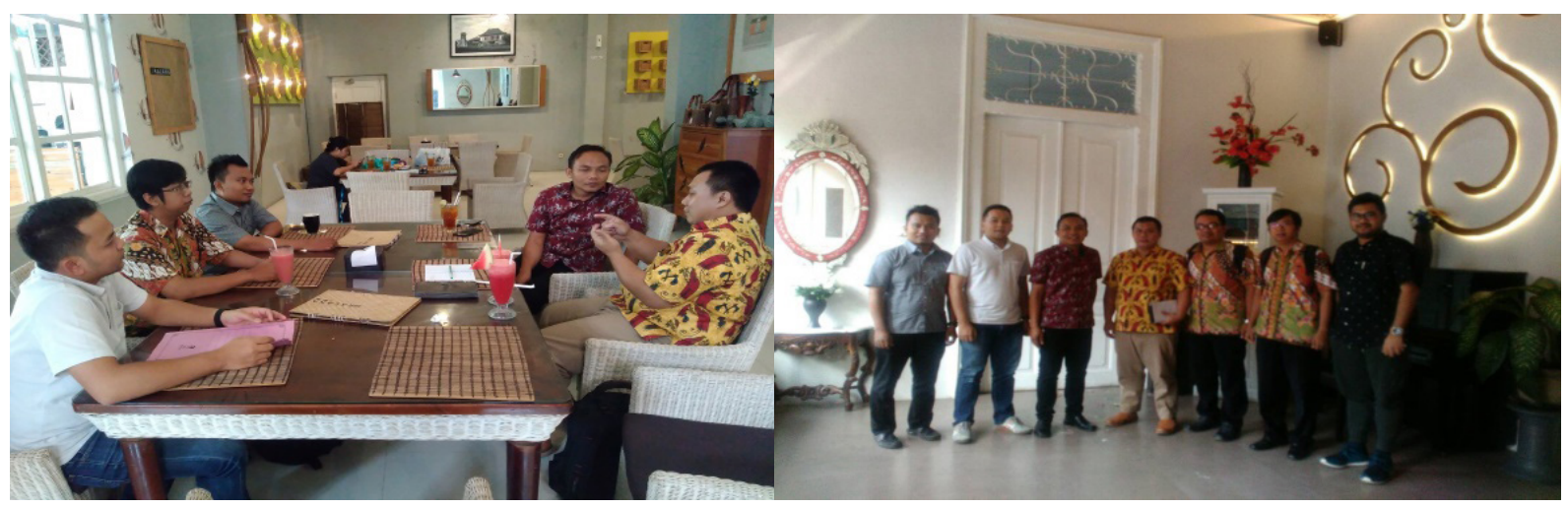

Gambar 7. Dan 8. Pertemuan MoU antara HIPMI Solo dengan USB-Tim IbPUD 


\section{Peningkatan Bahan Baku dan Produksi}

Pada peningkatan bahan baku singkong dan jagung maka kami Tim IbPUD memberikan pupuk cair probiotik untuk meningkatkan bahan baku tersebut. Dengan adanya pupuk cair probiotik tersebut dapat meningkatkan produksi bahan baku singkong dan jagung sebesar $20-30 \%$. Pada pendampingan pemupukan dilakukan oleh Tim IbPUD dengan mitra dan kolega mitra. Penyerahan pupuk cair probiotik disajikan pada Gambar 9.
Pada peningkatan bahan baku singkong dan jagung maka kami Tim IbPUD juga memberikan bantuan alat. Pada kelompok Sri Rejeki dengan produksi keripik singkong rasa gadung diberikan alat berupa mesin diesel alat pemotong singkong. Hasil menunjukkan bahwa produksi meningkat $50 \%$ di mana jika menggunakan alat manual menghasilkan 1 kwintal per hari sedangkan menggunakan mesin alat pemotong dapat menghasilkan 2 kwintal per hari. Mesin Pemotong singkong diberikan tersaji pada Gambar 10 (kanan).

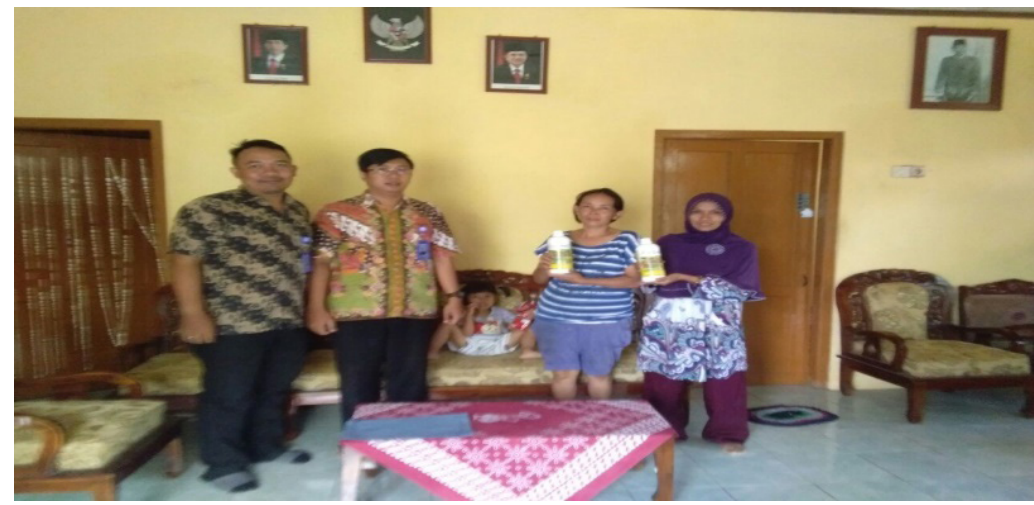

Gambar 9. Penyerahan Produk Pupuk Cair Probiotik Tanaman ke Mitra

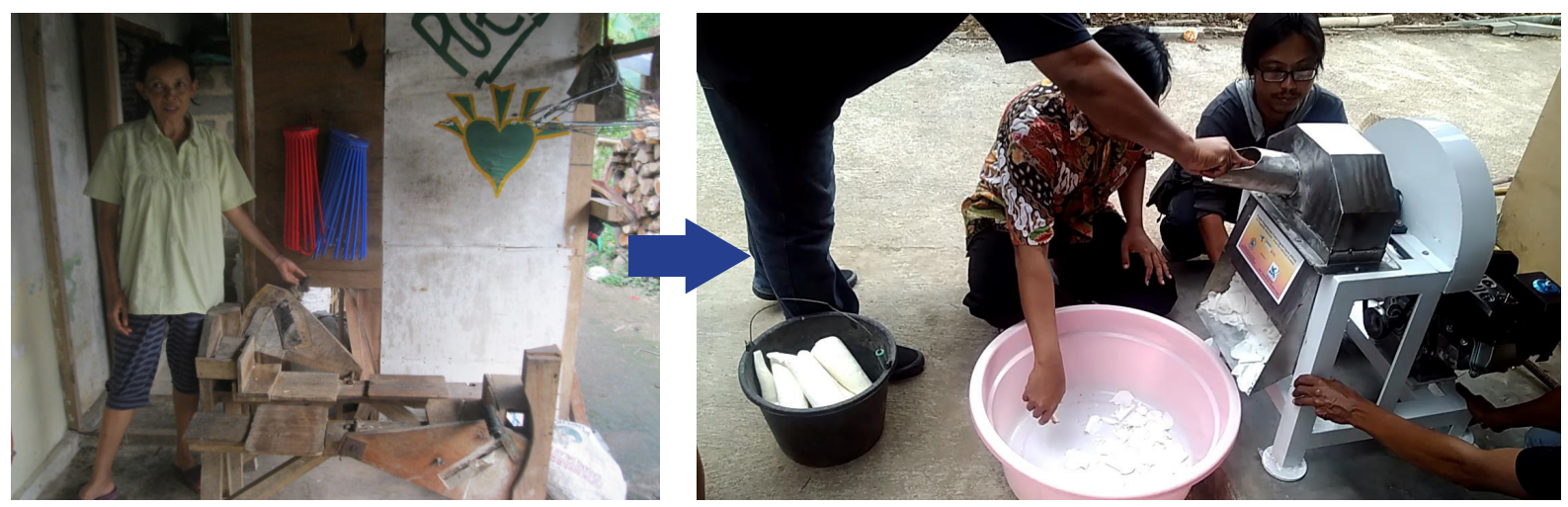

Gambar 10. Alat Pemotong Singkong Manual (Kiri) dan Mesin Pemotong singkong (Kanan)

\section{Peningkatan Manajemen Keuangan dan Pemasaran}

Pengelolaan sumber daya manusia, pemasaran dan sistem keuangan yang ada juga masih sangat kurang. Hal ini disebabkan tidak adanya tenaga kerja yang mempunyai keahlian khusus dalam bidang pengelolaan sistem keuangan, sehingga yang terjadi hanyalah pembukuan keuangan secara makro, yakni hanya memperhitungkan untung dan rugi tanpa melihat aspek keuangan secara detail. Hal inilah yang menjadi kendala untuk mengetahui berapa besar asset seluruhnya yang dimiliki oleh Kelompok Sri Rejeki dan Kelompok Wanita Tani Mukti Rahayu.

Salah satu bagian penting yang dilakukan dalam kegiatan pengabdian masyarakat ini adalah pengenalan software akuntansi dalam penyelesaian masalah yang terkait dengan pengelolaan sistem keuangan. Solusi yang kami dapatkan setelah berdiskusi 
dengan mitra adalah diperlukannya program pengelolaan data keuangan serta memberikan pelatihan dan pendampingan selama program tersebut dijalankan. Sebelum program dijalankan, sebelumnya akan diadakan pelatihan singkat tentang sistem keuangan secara manual dalam 8 kali pertemuan selama 1 bulan. Upaya untuk menjaga agar program tersebut dapat berjalan dengan baik dilakukan dengan cara melakukan pendampingan selama 8 bulan dan akan kami monitor secara intensif. Dengan demikian, ketikaterdapat permasalahan, dapat segera diatasi dan progam keuangantersebut dapat berjalan dengan baik. Sehingga Kelompok WaniTani akanmempunyai sistem akuntansi yang baik dan dapat dipertanggungjawabkan ketika dilakukan pemeriksaan.

Secara keseluruhan program pelatihan manajemen keuangan berbasis software telah dijalankan dengan target capaian 100\%. Software yang digunakan untuk pelatihan adalah aplikasi ACCURATE yang mana aplikasi ini telah dimiliki secara legal oleh Universitas Setia Budi Surakarta melalui transaksi pembelian. Kedua mitra telah menerima pelatihan aplikasi tersebut untuk pengelolaan manajemen keuangannya. Dengan adanya pelatihan tersebut diharapkan dapat meningkatkan kualitas manajemen dari masing-masing mitra.

Tahapan selanjutnya adalah memberikan pendampingan kepada kedua mitra dalam proses pengoperasian software tersebut. Pelatihan akan dilaksanakan mulai dari proses instalasi pada perangkat computer, pembuatan profile perusahaan, pengisian akun, proses transaksi pembelian dan penjualan, hingga pembuatan dan pencetakan laporan keuangan. Selain pendampingan, tahapan selanjutnya adalah evaluasi program. Evaluasi dilakukan dengan cara pengawasan pada saat pengoperasian aplikasi software agar tidak terjadi kesalahan pada saat pengisian profile perusahaan.

Pada peningkatan dalam bidang manajemen, Tim IbPUD telah menyelenggarakan Pelatihan Manajemen Keuangan Berbasis Sofware dan Sumber Daya Manusia Serta Pemasaran dengan pembicara dari Tim IbPUD yaitu Dian Indriana Hapsari, SE., M.Sc., Ak., CA dan asisten Tim IbPUD yaitu Didik Setyawan, SE., MM., M.Sc. Kedua pembicara atau pemateri merupakan Dosen Tetap Universitas Setia Budi Surakarta pada hari Jumat tanggal 25 Agustus 2017 bertempat di Universitas Setia Budi Surakarta.

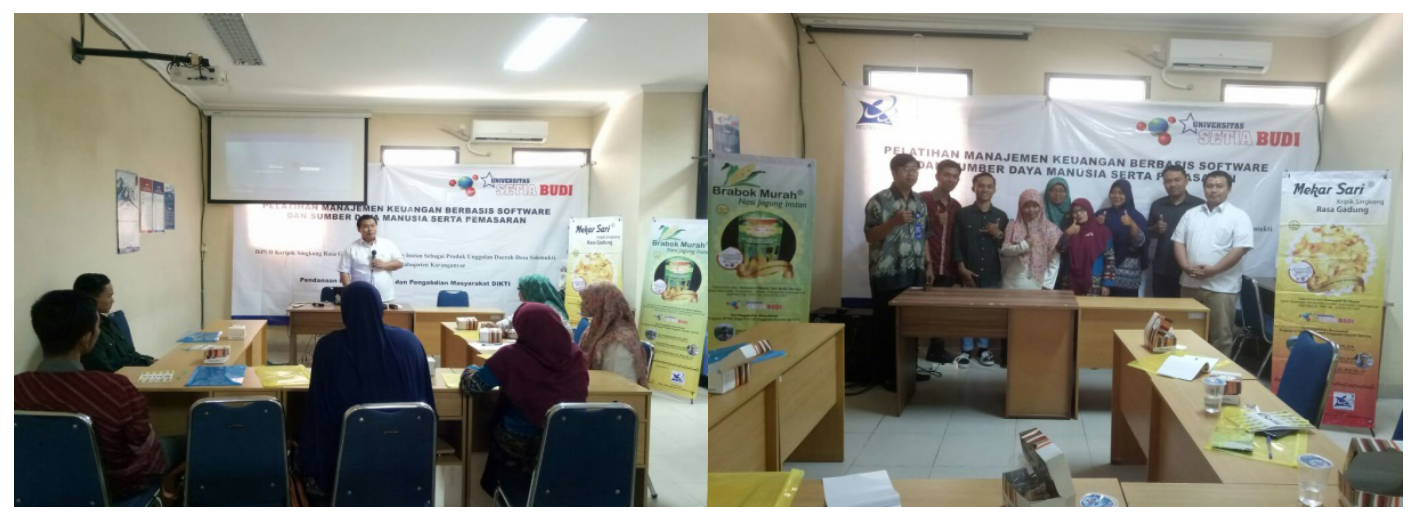

Gambar 11. dan 12 Penyampaian Materi Pelatihan Manajemen SDM dan Pemasaran

Pada sesi kedua pelatihan tersebut diagendakan Pelatihan Manajemen Keuangan Software Akuntasi $M Y O B$ dan Accurate.
Dian Indriana Hapsari, SE., M.Sc., Ak., CA, disajikan dalam Gambar 13, 14, 15 dan 16. 


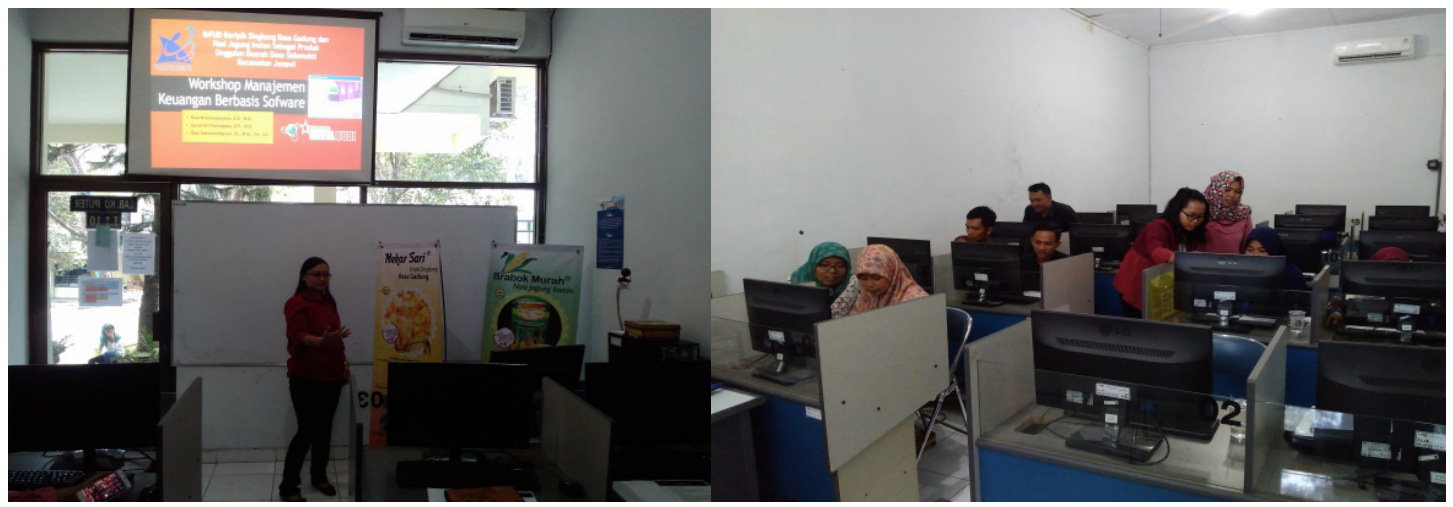

Gambar 13. dan 14 Pelatihan Manajemen Keuangan Berbasis Software

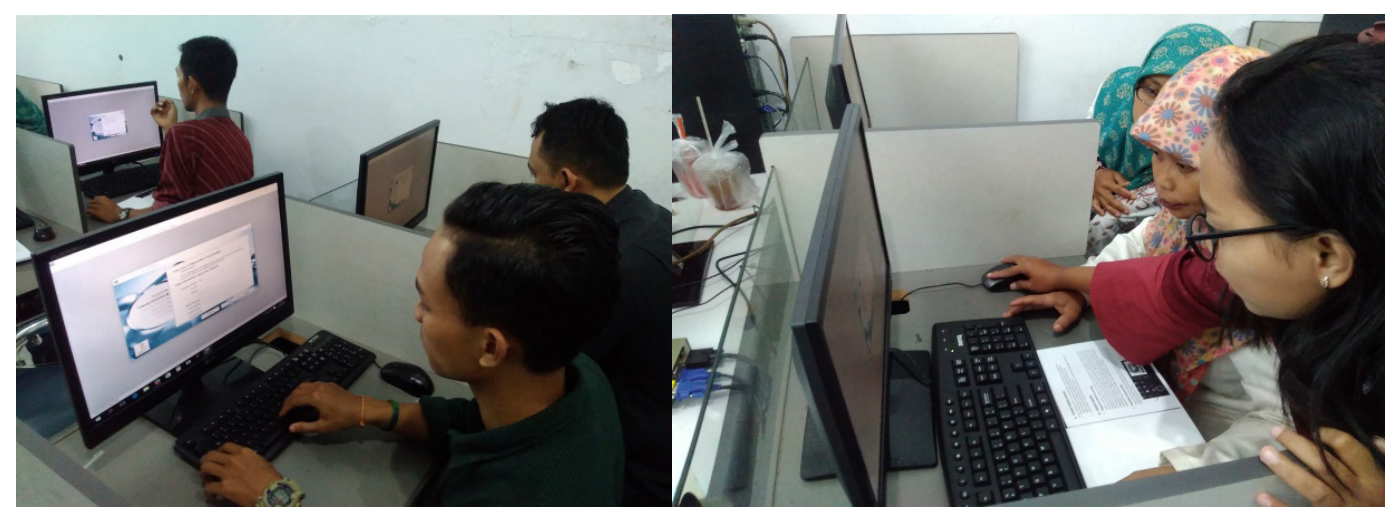

Gambar 15. dan 16 Pelatihan Manajemen Keuangan Berbasis Software

\section{KESIMPULAN DAN SARAN}

\section{Kesimpulan}

1. Tim IbPUD Jenawi telah melakukan pendekatan awal kerja sama dengan Dinas Perdagangan, Tenaga Kerja dan Koperasi dengan ikutnya berbagai pameran-pameran dari Kabupaten Karanganyar.

2. Tim IbPUD Jenawi telah melakukan pendekatan awal kerja sama dengan Himpunan Pengusaha Muda Indonesia (HIPMI) Cabang Solo.

3. Produksi keripik meningkat 50\% setelah menggunakan mesin alat pemotong singkong bermesin diesel dapat menghasilkan 2 kwintal per hari.

4. Produksi nasi jagung instan meningkat dari $10 \mathrm{~kg} /$ hari menjadi $25 \mathrm{~kg} / \mathrm{hari}$ setelah menggunakan oven besar beserta pengatur suhu.

\section{Saran}

1. Perlunya peningkatan kerjasama antara Dinas di Pemerintah Daerah dengan tindak lanjut MoU dengan Tim IbPUD untuk menunjang program IbPUD.

2. Perlunya pendampingan terakait promosi dan pemasaran serta keuangan dengan membuat web profile dan pemasaran berbasis online.

3. Perlunya peningkatan kualitas produk sebagai produk unggulan daerah di Kabupaten Karanganyar.

\section{UCAPAN TERIMA KASIH}

Kami mengucapkan terima kasih kepada Direktorat Riset dan Pengabdian Masyarakat Direktorat Jenderal Penguatan Riset Pengembangan Kementerian Riset, Teknologi dan Pendidikan Tinggi Sesuai dengan Kontrak Pengabdian Nomor: 010/ LPPM-USB/IbPUD/IV/2017 yang telah membiayai kegiatan IbPUD (PPPUD) Keripik Singkong Rasa Gadung Sebagai Produk Unggulan Daerah Desa Sidomukti Kecamatan Jenawi Kabupaten Karanganyar 


\section{DAFTAR PUSTAKA}

Chandra, G., 2002, Strategi dan Program Pemasaran, Yogyakarta : Andi,

DeLozier,M. W. 1976. The Marketing Communication Process. Mc. Grawhill, Inc.

Kotler, P. 1994. Manajemen Pemasaran Edisi 2 Jilid 1. Jakarta: Erlangga.

Kotler, P. 1994. Manajemen Pemasaran Edisi 2 Jilid 2. Jakarta: Erlangga.

Kotler, P \& G. Armstrong. 2009. Prinsip-Prinsip Pemasaran Jilid 1 Edisi 12. Jakarta: Indeks

Kotler, P \& G. Armstrong. 2008. Prinsip-Prinsip Pemasaran Jilid 2 Edisi 12. Jakarta: Indeks

Kotler, P \& G. Armstrong. 2004. Dasar-Dasar Pemasaran Jilid 2 Edisi 12. Jakarta: Indeks

McCarthy, J. and Perreault, W. 1995. Intisari Pemasaran Sebuah Ancangan Manajerial Global. Jakarta: Binarupa Aksara.

Swainn, W, Perceptions of IMC after a Decade of Development: Who's at the Wheel, and How Can We Measure Success?, , March 2004, Journal of Advertising Research

Swastha, B. 1984. Azas-Azas Marketing Edisi 3. Yogyakarta: Liberty.

Swastha, B dan Irawan. 1996. Manajemen Pemasaran Modern Edisi 2.

Yogyakarta: Liberty.

Tjiptono, Fandy. 2008. Strategi Pemasaran Edisi 2. Yogyakarta: Penerbit Andi

Uchjana, Onong. 2002. Ilmu Komunikasi : Teori dan Praktek. Bandung: PT Remaja Rosdakarya.

Uyung Sulaksana, 2004, Integrated Marketing Communications: Teks \& Kasus, Yogyakarta. Pustaka Pelajar

Widyatama, Rendra. 2005. Pengantar Periklanan. Jakarta: Buana Pustaka Indonesia.

Schultz, Don E., Philip J Kitchen, Integrated Marketing Coammunications in U.S. Exploratory Study. 